\title{
FINANCIAMENTO DO SETOR RURAL: UMA ANÁLISE DOS PROGRAMAS PROCERA E PRONAF E O CASO DOS ASSENTAMENTOS RURAIS DO PONTAL DO PARANAPANEMA - SP
}

\author{
FINANCIACIÓN DEL SECTOR RURAL: UN ANÁLISIS DE LOS \\ PROGRAMAS PROCERA Y PRONAF Y EL CASO DE LOS \\ ASENTAMIENTOS RURALES DEL PONTAL DEL PARANAPANEMA - SP
}

FINANCING OF THE RURAL SECTOR: AN ANALYSIS OF THE PROCERA AND PRONAF PROGRAMS AND THE CASE OF RURAL SETTLEMENTS OF THE PONTAL OF THE PARANAPANEMA - SP

\section{Nivea Massaretto Verges Mestranda do Programa de Pós-Graduação em Geografia da Universidade Estadual Paulista - Campus de Presidente Prudente. nivea_massa@yahoo.com.br}

\begin{abstract}
Resumo: Atualmente se discute o acesso ao crédito rural no Brasil, destacando sua escassez e ineficiência para com os pequenos produtores. Neste sentido, o trabalho buscou analisar programas governamentais criados para atender, principalmente, à esses produtores e analisar a realidade dos assentamentos rurais, a fim de fazer uma comparação entre teoria e realidade e identificar os problemas e possíveis soluções, utilizando informações do relatório de consultoria "As políticas públicas de crédito para os assentamentos rurais no Brasil" e dados do Censo da Reforma Agrária de 2002. Os resultados apontaram as dificuldades enfrentadas pelos assentados para sobrevivência em seus lotes e no acesso ao crédito, e também mostraram as exigências que são impostas pelas instituições financeiras e falta de incentivo pelo Estado. Isso tudo pôde justificar a ineficiência dos programas oficiais de crédito rural.
\end{abstract}

Palavras-Chave: Crédito rural; parcerias; assistência técnica; cooperativas; garantias.

Resumen: Actualmente se ha discutido sobre el acceso al crédito rural en Brasil, destacando su escasez y la ineficiencia hacia la los pequeños productores. En este sentido, el estudio trata de analizar los programas gubernamentales creados para atender principalmente a los productores y analizar la realidad de los asentamientos rurales con el fin de hacer una comparación entre la teoría y la realidad e identificar los problemas y posibles soluciones, utilizando la información del informe de consultoría "La política pública de crédito a los asentamientos rurales en Brasil" y los datos del Censo de la Reforma Agrari de 2002. Los resultados indicaron las dificultades que enfrentan los colonos a sobrevivir en sus lotes y el acceso al crédito, y también mostró los requisitos impuestos por las instituciones financieras y la falta de incentivos por parte del Estado. Todo esto podría justificar la ineficacia de los programas oficiales de crédito rural.

Palabras Clave: Crédito rural; asociaciones; asistencia técnica; cooperativas; garantías.

Abstract: Currently discussing access to rural credit in Brazil, highlighting its scarcity and inefficiency to small producers. In this sense, the work was examine government programs designed to serve primarily to those producers and analyze the reality of rural 
settlements in order to make a comparison between theory and reality and identify problems and possible solutions, using information from the consultancy report "the public policy of credit to the rural settlements in Brazil" and the Census of Agrarian Reform of 2002. The results showed the difficulties faced by the settlers to survive on their lots and access to credit, but also showed that the requirements imposed by financial institutions and lack of incentives by the state. This all could justify the inefficiency of public programs for rural credit.

Keywords: Rural credit; partnerships; technical assistance; cooperative; guarantees

\section{INTRODUÇÃO}

Dois programas governamentais de crédito rural são apontados como os principais para atender às demandas da agricultura familiar e dos pequenos produtores: o Programa de Crédito Especial para Reforma Agrária - PROCERA e o Programa Nacional de Fortalecimento da Agricultura Familiar - PRONAF, que surgiram a partir de meados dos anos 80 .

Contudo, estudos sobre o financiamento do setor rural indicam que, apesar de muitos programas oficiais privilegiarem os pequenos produtores, estes ainda não são suficientes para atender à demanda destes produtores rurais e, além disso, o crédito ainda está concentrado entre os grandes produtores, que são aqueles que oferecem maiores garantias. O crédito também está mais direcionado para as culturas com forte grau de integração, principalmente aquelas destinadas à exportação.

Na Região do Pontal do Paranapanema (Figura 1), conhecida pelos diversos conflitos de luta pela terra, durante a década de 80 , ocorreu uma série de processos de desapropriação de terras por parte dos Governos Estadual (Instituto de Terras do Estado de São Paulo - ITESP) e Federal (Instituto Nacional de Colonização e Reforma Agrária - INCRA), resultando nos assentamentos rurais. Estes assentamentos, atualmente, estão sendo pressionados pelas usinas de açúcar e álcool, instaladas nesta região, a arrendarem suas terras para o plantio da cana-de-açúcar em troca de melhoria de suas rendas. Este fato levou muitos assentados a realizarem parcerias com essas usinas, visando a melhoria de suas condições de vida, entretanto, os resultados de tais parcerias não foram positivos.

A partir dessas afirmações, fez-se um questionamento sobre o por que dos assentados realizarem essas parcerias com empresas privadas e não tentarem o acesso ao crédito através dos programas oficiais do governo, a fim de produzirem em seus lotes de 
forma autônoma e gerarem renda? Quais são os problemas para o financiamento, ou seja, porque estes programas não conseguem atingir seu objetivo de atender aos pequenos produtores e quais seriam as possíveis soluções para o financiamento, especificamente dos assentados.

Este trabalho foi motivado pela preocupação em responder esses questionamentos e buscando soluções para um financiamento coerente à realidade dos assentados. Nossas hipóteses são de que os assentados encontram muita dificuldade em obter o crédito rural e, como a parceria com a usina não tinha necessidade de muita burocracia, esse foi um caminho mais viável encontrado pelos assentados para conseguir melhorar a renda. E, em relação aos problemas do financiamento, acredita-se que além destes ainda serem pensados como uma forma de combater a pobreza e não levar em conta o desenvolvimento desses produtores, há exigências muito complexas que os assentados não conseguem corresponder. A forma dos programas ainda está voltada àqueles que já possuem um grau de desenvolvimento e não para aqueles que estão iniciando sua produção no campo. Além disso, a região onde se localizam os assentamentos é de áreas bastante arenosas, com processos de erosão e de baixa fertilidade, o que dificulta ainda mais o fato do assentado não ter recursos, nem capacitação técnica para correção do solo e, com as parcerias, isso seria possível através da atuação e investimento da usina.

Para responder esses questionamentos, o trabalho teve como objetivo principal analisar os programas de financiamento do setor rural para assentamentos rurais, PROCERA e PRONAF, e analisar a realidade desses assentamentos fazendo uma comparação entre eles, a fim de identificar os problemas e possíveis soluções para o financiamento. Também será apresentada caracterização dos assentamentos rurais selecionados e a área em que se encontram: PE Santa Apolônia, PE Alcídia da Gata e PA Antonio Conselheiro II e um levantamento bibliográfico da expansão da cana-deaçúcar na Região do Pontal do Paranapanema e das parcerias realizadas entre usina e assentados rurais.

\section{PROCEDIMENTOS METODOLÓGICOS}

Para o trabalho, foram selecionados três assentamentos da região do Pontal do Paranapanema - SP: Projeto de Assentamento Estadual (PE) Alcídia da Gata, Projeto de 
Assentamento Federal (PA) Antonio Conselheiro II e PE Santa Apolônia. O PE Alcídia da Gata foi selecionado por ter participado das parcerias entre usina e assentados, já o Antonio Conselheiro II e Santa Apolônia foram indicados por técnicos do ITESP e INCRA uma vez que muitos assentados estão em uma situação financeira mais favorável devido ao cultivo de diversas culturas e comercialização dos produtos.

A caracterização dos assentamentos e das áreas, assim como o histórico da expansão da cana-de-açúcar e das parcerias entre usina e assentados foram realizados através de levantamento bibliográfico.

A pesquisa sobre os programas de financiamento do setor rural para os assentamentos foi realizada com base no relatório de consultoria "As políticas públicas de crédito para os assentamentos rurais no Brasil", de Regina Angela Landim Bruno e Marcelo Miná Dias, que teve como objetivo construir uma análise sobre as características, potenciais e impasses desses programas criados para ofertar crédito em condições especiais aos agricultores assentados e familiares.

A caracterização da realidade dos assentamentos se realizou com os dados obtidos através do Censo da Reforma Agrária de 2002. Neste censo, existem respostas concedidas pelo próprio beneficiário e pelo responsável do projeto de assentamento, porém, as respostas são diferentes e, para isso, decidiu-se optar pela resposta do beneficiário, já que este tem mais afinidade com a realidade do que o próprio técnico. Quando as respostas dos beneficiários foram diferentes, foi utilizada a média.

\section{DISCUSSÃO E ANÁLISE DE RESULTADOS}

\section{OS ASSENTAMENTOS RURAIS DA REGIÃO DO PONTAL DO PARANAPANEMA}

A região do Pontal do Paranapanema está situada no extremo Oeste Paulista (Figura 1). A região se tornou bastante conhecida devido aos vários conflitos de luta pela terra envolvendo os grandes latifundiários e movimentos sociais. Atualmente, observa-se um conflito que envolve um novo sujeito, representado pela oligarquia fundiária do agronegócio, na qual empresários do setor apresentam projetos de expansão da monocultura da cana-de-açúcar, com discurso de que trarão benefícios à região.

A região do Pontal do Paranapanema abrange trinta e dois municípios. Neste trabalho, dentre as diversas classificações das denominações de Pontal, adotamos a definição da 
UNIPONTAL - Associação dos Municípios do Pontal do Paranapanema, uma das classificações mais amplas. Os assentamentos selecionados nesta pesquisa estão localizados nos municípios de Teodoro Sampaio - SP e Mirante do Paranapanema, conforme figura 1:

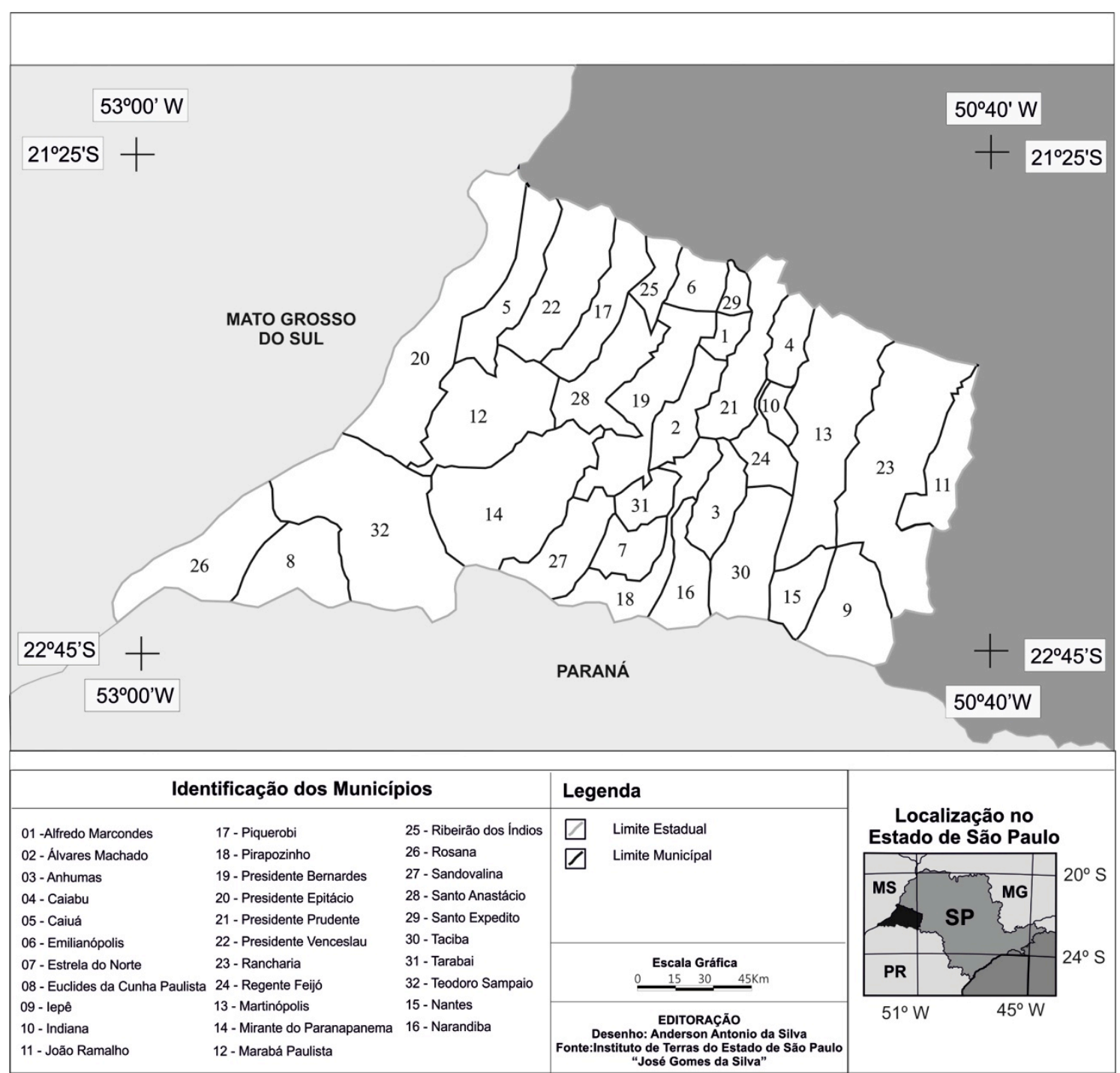

Figura 1. Localização dos Municípios da Região do Pontal do Paranapanema. Fonte: Relatório de Impactos Socioterritoriais (RIST) - 2006.

O Assentamento Santa Apolônia, criado no ano de 1997, e Antonio Conselheiro II, criado no ano de 1999, estão localizados no município de Mirante do Paranapanema e o Assentamento Alcídia da Gata, criado em 1999, no município de Teodoro Sampaio.

De acordo com o Mapa Geomorfológico do Estado de São Paulo na escala 1: 500.000, elaborado por Ross e Moroz (1996), os assentamentos rurais encontram-se localizados na Bacia Sedimentar do Paraná (morfoestrutura) e no Planalto Ocidental Paulista (morfoescultura), mais precisamente no Planalto Centro Ocidental, cujas formas de relevo predominantes são as colinas amplas e baixas com altimetria em torno 
de 300 a 600 metros, declividade variando entre 10 a 20\% e predomínio de Latossolos e de Argissolos.

Quanto aos aspectos geológicos, os assentamentos rurais estão situados sob a Formação Caiuá (Grupo Bauru). Conforme é especificado pelo Instituto de Pesquisas Tecnológicas (IPT) esta unidade é constituída por “... arenitos finos a médios, com grãos bem arredondados, com coloração arroxeada típica, apresentando abundantes estratificações cruzadas de grande a médio porte. Localmente ocorrem cimento e nódulos carbonáticos" (IPT, 1981:48).

Referente aos tipos de solos, de acordo com o Mapa Pedológico do Estado de São Paulo (OLIVEIRA, 1999), na área de estudo encontram-se os Argissolos Vermelhos (PV4) e os Latossolos Vermelhos (LV45). Essa classe de solo é resultado da ação intempérica sobre os arenitos da Formação Caiuá - Grupo Bauru.

Os solos onde se situam os assentamentos rurais predominam os Latossolos e, através de análises físicas e químicas realizadas por Massaretto (2010), verificou-se que são solos extremamente arenosos e de baixa fertilidade. $\mathrm{O}$ elevado percentual de areia está relacionado à formação geológica na qual os assentamentos estão localizados, ou seja, as formações geológicas areníticas do Grupo Bauru (Formação Caiuá). Em relação à fertilidade, os solos dos assentamentos apresentam $\mathrm{pH}$ ácido, baixa saturação de bases, baixo teor de matéria orgânica, o que indicada baixa fertilidade.

Através dos dados apresentados, percebe-se que as condições físicas e de fertilidade da área onde os assentamentos estão situados não são favoráveis à agricultura, exceto se houver correção do solo. Entretanto, as condições sociais e financeiras dos assentados não permitem que estes possam melhorar a situação dos solos de seus lotes. Com a expansão da cana-de-açúcar na região, esta se tornou uma possibilidade, através das parcerias, de geração de renda a esses assentados.

\section{AS PARCERIAS ENTRE USINAS E ASSENTAMENTOS RURAIS}

Com a expansão do monocultivo da cana na Região do Pontal do Paranapanema, verificou-se a realização de parcerias entre os assentados rurais e os usineiros para o plantio da cana. Percebe-se que, em meio às dificuldades enfrentadas pelos assentados, o plantio da cana tornou-se uma alternativa financeira para melhorarem suas rendas e, consequentemente, as condições de vida. Assim, tem-se que, 
A falta de uma política agrícola adequada e/ou de um projeto alternativo, que garanta a viabilização da produção e, consequentemente, a permanência dos assentados na terra em condições dignas, os torna fragilizados e, portanto, vulneráveis às pressões e estratégias do capital, que atua com o aval do Estado (BARRETO; OLIVEIRA; THOMAZ JUNIOR, 2008: 8).

No ano de 1993 ocorreu a primeira tentativa de produzir cana-de-açúcar em lotes de assentamentos rurais da região do Pontal do Paranapanema. Segundo Gonçalves (2009), esta iniciativa partiu da Destilaria Alcídia, que apresentou ao ITESP um projeto para o plantio de cana em lotes do Assentamento Água Sumida no município de Teodoro Sampaio, quando 11 dos 121 lotes entraram na "parceria". Dois anos após o início do contrato a Destilaria Alcídia elaborou uma avaliação da "parceria", onde dizia que os resultados obtidos estavam dentro do previsto no projeto elaborado em 1993.

No final do ano de 1995, o Departamento de Assentamento Fundiário, do ITESP, solicitou ao Departamento de Geografia da Universidade Estadual Paulista UNESP - de Presidente Prudente, um parecer "sobre a viabilidade da introdução da cana de açúcar nos assentamentos, tendo como base o projeto piloto, envolvendo a Destilaria Alcídia e o assentamento Água Sumida.” (GONÇALVES, 2009: 2). Um grupo de geógrafos realizou pesquisa de campo junto aos assentados e a empresa para elaborar o parecer técnico-científico. No parecer relataram a contradição representada pelo cultivo da cana-de-açúcar em assentamentos rurais. Após o parecer, não foram mais firmados nenhum contrato entre a destilaria e os assentados.

Entretanto, a Destilaria Alcídia voltou a firmá-los no ano de 2002, ano em que o ITESP - lançou em 24 de outubro, a Portaria $\mathrm{n}^{\circ}$. 075, que permitia a locação de serviços dos assentados às agroindústrias. No dia 27 de julho de 2004, o ITESP fez uma revisão nas medidas antes estabelecidas pela Portaria $n^{\circ} .075 / 2002$ e relançou na portaria $n^{\circ} .077$ as revisões.

Os contratos de "parceria" entre assentados e a Destilaria Alcídia firmados em 2002 deveriam terminar em 2009, entretanto, a partir de 2008 a destilaria já não utilizava da produção nos assentamentos em parcerias. Esta foi a parceria aceita pelos assentamentos os quais estão embasados este trabalho. Segundo os assentados o contrato de "parceria" proposto pela usina seria de duas safras - 2002 a 2009, período em que ficariam arrendados até 30\% do lote, sendo em média seis hectares.

Além da área permitida para o plantio da cana, no contrato constava a concessão para a usina fazer o empréstimo junto ao PRONAF - Programa Nacional de 
Fortalecimento da Agricultura Familiar em nome do assentado. Alguns assentados afirmaram que no empréstimo a Usina era a avalista e o assentado o titular do empréstimo, que teria três anos para pagar o banco. Após a colheita a usina pegava o dinheiro, mas era o assentado o responsável pelo pagamento. Um dos assentados afirmou que todo o dinheiro do empréstimo foi para a usina, os assentados nunca obtiveram o dinheiro.

Atualmente, a Destilaria Alcídia pertence ao Grupo Odebrecht, uma corporação brasileira transnacional do setor de construção, que realizou a compra da destilaria no ano de 2007, passando a se chamar ETH - Unidade Alcídia (ETH é a abreviação da palavra etanol na língua inglesa) (FERNANDES, GONÇALVES, 2009). Este é mais um problema que os assentados enfrentaram, pois, segundo seus relatos, quando foi feita a tentativa de diálogo com a usina para tratar dos prejuízos com o plantio da cana, a direção da ETH afirmou que não tinha nenhuma responsabilidade sobre a parceria, já que a compra da Destilaria Alcídia foi realizada após a assinatura do contrato, sendo assim, a ETH não era responsável por qualquer problema que tenha ocorrido.

$\mathrm{O}$ que se percebe é que em meio às dificuldades enfrentadas pelos assentados, estes tentam buscar novas saídas para que possam permanecer em seus lotes. Todavia, sem as políticas públicas, com incentivo por parte do Estado, fica cada vez mais difícil encontrar assentamentos de reforma agrária que diversifiquem sua produção.

Dessa forma, nota-se a importância que os programas oficiais de financiamento têm para os assentados, pois se trata de um instrumento fundamental para o auxílio e posterior desenvolvimento desses assentamentos. Nesse sentido, será feita uma exposição da política de financiamento rural no Brasil, voltada especialmente, aos produtores assentados.

\section{POLÍTICA DE FINANCIAMENTO RURAL NO BRASIL}

As políticas públicas de financiamento do setor rural são extremamente importantes para o desenvolvimento das atividades agropecuárias, principalmente, dos pequenos produtores, os quais utilizam esses tipos de financiamentos a fim de conseguirem melhorar seus rendimentos e a comercialização de seus produtos. Entretanto, o que se tem observado é a escassez e ineficiência dessas políticas por parte do Estado, afetando, dessa forma, os pequenos produtores e a produção agrícola no que diz respeito aos alimentos básicos. 
Segundo Nascimento et al (2007), com a criação do Sistema Nacional de Crédito Rural (SNCR), em 1965, visando a integração da agricultura para fins da modernização da economia nacional, tem início o financiamento rural no Brasil. Anterior a data de criação da SNCR, é importante destacar que desde os anos 60, vários países em desenvolvimento iniciaram a criação de uma série de projetos e programas dirigidos, principalmente às populações rurais mais pobres, com o objetivo de minimizar a pobreza dessa população assim como fornecer alternativas de financiamento que lhes fossem possíveis de adquirir e, principalmente, quitar o financiamento (BRUNO \& DIAS, 2004).

A lógica dominante da atividade financeira parte do princípio de que um crédito só será ofertado se cobrir os custos operacionais, ser for rentável e, acima de tudo, segura para os bancos que as possibilitam. Num sentido contrário, os programas oficiais são elaborados a fim de estabelecer condições especiais de contratação e pagamento do financiamento e tentar amenizar a resistência dos agentes financeiros para oferecer crédito aos agricultores familiares e agricultores assentados (BRUNO; DIAS, 2004: 7).

No caso dos agricultores assentados, os programas oficiais são de fundamental importância, pois, em muitos casos, quando o sujeito conquista seu lote, este não apresenta condições favoráveis para as atividades agropecuárias, além disso, "na maioria dos casos, são agricultores pobres, com baixíssima ou nenhuma capacidade própria de investir em melhorias de seu lote ou do assentamento como um todo" (BRUNO; DIAS, 2004: 7). Esses aspectos dificilmente farão o assentado conseguir um financiamento na lógica do mercado financeiro dominante, já que este impõe muitas exigências, o que demostra, dessa forma, a importância dos programas oficiais para os assentados.

Dentre os programas criados para o financiamento do setor rural, dois são considerados de grande importância para os agricultores assentados: o PROCERA e o PRONAF.

O Programa de Crédito Especial para a Reforma Agrária - PROCERA - foi instituído em 1986, com o objetivo de garantir aos agricultores assentados acesso a recursos financeiros, em condições diferenciadas, para investimentos em processos produtivos, a fim de aumentar a produção dos assentados e possibilitar a inserção nos mercados e, dessa forma, os assentados se emancipariam, obtendo a titulação definitiva 
da terra. Segundo Bruno e Dias (2004), esta foi uma visão simplista do processo de desenvolvimento dos assentamentos, pois,

A eficácia do programa de crédito era, neste caso, associado aos processos de mudança da base técnica dos processos de produção, aos moldes do malfadado processo de modernização da agricultura (BRUNO; DIAS, 2004: 13).

O PROCERA era dividido em três linhas de crédito: custeio, investimento e coletivo. Cada família recebia um crédito de implantação no momento em que eram assentadas, com intuito de auxiliar a instalação das famílias no lote até que essas obtivessem renda do trabalho na terra e, após essa instalação, os assentados tinham direito ao PROCERA.

Para os autores, apesar de o programa ter permitido a introdução de novas tecnologias, geração de renda e patrimônio, dinamização do comércio local dos municípios próximos aos assentamentos, maior atuação política dos assentados, houve limitações e impasses para sua execução, até mesmo pela avaliação do governo em que se afirmou que o programa não atingiu seu objetivo principal de emancipação do produtor assentado em relação ao Estado.

Dentre os impasses, pode-se citar a insuficiência, a descontinuidade e a demora nos processos de liberação, contratação e pagamento dos mesmos, o que trouxe consequências negativas quanto à produção e renda dos agricultores assentados, com reflexo direto sobre a capacidade de pagamento. Além disso, o acesso ao crédito estava associado a determinados pacotes técnicos de modernização da agricultura, o que gerou forte dependência dos assentados em relação às assistências, que, quase sempre, não ocorreram.

A qualidade técnica dos projetos elaborados também se tornou um problema no PROCERA, pois muitos foram elaborados sem adequação da realidade dos assentamentos e da demanda dos agricultores. Outro grande problema do programa esteve relacionado com o fato da não criação de mecanismos que elevassem as taxas de retorno dos investimentos feitos, ou seja, o governo assumia elevados riscos, o que gerou a falência do programa. Além disso, a falta de políticas públicas complementares a de crédito rural colocavam os assentados a enfrentarem a terra em condições bastante precárias para o cultivo. 
Dessa forma, surgiu a ideia do agricultor moderno, de perfil empresarial, disposto a aprender e praticar a disciplina financeira, características essas que influenciaram a extinção do PROCERA à partir de sua integração ao PRONAF.

O Programa Nacional de Fortalecimento da Agricultura Familiar surgiu num contexto marcado pelas intensas mobilizações reivindicando ações governamentais à favor da Reforma Agrária, envolvendo a questão de crédito rural. Em 1996, o PRONAF passou a ser um programa governamental e a operar recursos do Orçamento Geral da União (OGN).

O programa foi dividido em três linhas de atuação: política agrícola (crédito, preços e tributação), oferta de serviços de apoio (pesquisa, assistência técnica e extensão rural e reforma agrária) e apoio à formação de infraestrutura física e social. Esses eixos foram divididos em três grandes modalidades:

a) PRONAF - Infraestrutura e Serviços Municipais;

b) PRONAF - Capacitação;

c) PRONAF - Crédito Rural

O PRONAF é dividido em oito grupos, nas quais as modalidades e linhas de crédito foram organizadas de modo a atender as demandas dos grupos que beneficiam e aos segmentos, setores ou grupos regionais de agricultores familiares.

Bruno \& Dias (2004), afirmam que, a exemplo do que já havia ocorrido com PROCERA, o programa representa avanços na elaboração e gestão de políticas públicas cujo objetivo geral é romper com a escassez de crédito e as dificuldades de acesso ao crédito por parte dos agricultores familiares, porém, o PRONAF também apresenta alguns impasses.

Um primeiro impasse se refere à distribuição dos recursos, no qual se observa que aqueles que têm produção de culturas relacionadas aos complexos agroindustriais e para o mercado externo conseguem com mais facilidade o financiamento, ou seja, regiões como Sul e Sudeste são aquelas que apresentam maiores números de financiamentos. Este é um impasse, pois o programa é criado para fortalecer a agricultura familiar, que, na maioria das vezes, apresentam produção voltada a alimentos de necessidade básica, como feijão, mandioca, arroz, frutas, dessa forma, o programa não atinge o objetivo de auxiliar os agricultores menos desenvolvidos, tendo 
então uma distribuição desigual do Programa (tanto em relação às regiões quanto a de culturas financiadas).

Ao contrário do PROCERA, no PRONAF os bancos assumem maiores riscos com os financiamentos, porém, criam maiores exigências e dificuldades, favorecendo àqueles assentados que estão mais desenvolvidos, ou seja, que oferecem maiores garantias e estão mais integrados aos mercados.

A relação entre os agricultores familiares e as instituições financeiras são extremamente complicadas por vários motivos. O fato de não apresentarem garantias, baixo nível educacional e falta de práticas contábeis completam a imagem construída a respeito dos tomadores de crédito em pequena quantidade (BRUNO; DIAS, 2004).

Os agricultores enfrentam elevados custos de transação e não possuem o conhecimento sobre as exigências e demandas do programa de crédito. Além disso, encontram dificuldades na tentativa de acesso ao crédito, como a disponibilidade de tempo, de energia e de recursos financeiros para se deslocarem até as agências bancárias, providenciarem os documentos exigidos e provarem ter as garantias necessárias.

Os bancos, por sua vez, também desconhecem a diversidade das lógicas próprias dos sistemas sociais e produtivos que caracterizam a exploração agrícola familiar. Fica clara a distância entre os bancos e as boas intenções da política pública de promoção do desenvolvimento rural, neste caso implementado pelo PRONAF.

Diante da descrição dos dois principais programas de crédito rural aos agricultores assentados, faremos uma caracterização dos três assentamentos selecionados, comparando a realidade dos assentados com os apontamentos das políticas de crédito rural.

\section{A REALIDADE DOS ASSENTAMENTOS RURAIS DO PONTAL DO PARANAPANEMA}

Através dos dados obtidos pelo Censo da Reforma Agrária de 2002, apresentaremos a caracterização dos três assentamentos selecionados para este trabalho. O gráfico 1 apresenta famílias que moram no projeto de assentamento, ressaltando que os Assentamentos Santa Apolônia e Alcídia da Gata são estaduais e o Antonio Conselheiro II, federal. 
Gráfico 1. Número de famílias que moram nos assentamentos.

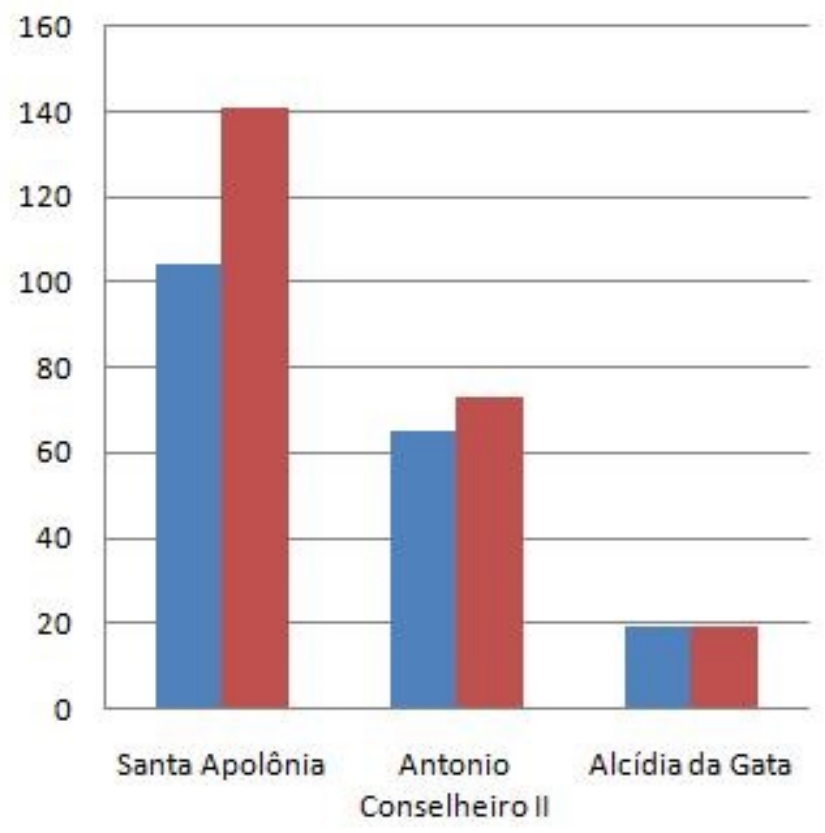

Fonte: Censo da Reforma Agrária de 2002
Capacidade do Assentamento, conforme portaria de criação

Número atual de familias morando em casas individuais

A capacidade do assentamento é coerente com o número de lotes que cada assentamento possui. Entretanto, ao observarmos a realidade, o número de famílias que moram é superior à capacidade do assentamento, exceto Alcídia da Gata. Santa Apolônia de 104 para 141 e Antonio Conselheiro II de 65 para 73.

Quadro 1. Informações gerais da área dos assentamentos.

\begin{tabular}{|c|c|c|c|c|}
\hline $\begin{array}{c}\text { Nome do } \\
\text { Assentamento }\end{array}$ & $\begin{array}{c}\text { Área total do } \\
\text { (em } \\
\text { hectares) }\end{array}$ & $\begin{array}{c}\text { Área média } \\
\text { dos lotes (em } \\
\text { hectares) }\end{array}$ & $\begin{array}{c}\text { Área de Preservação } \\
\text { Permanente (APP) } \\
\text { (em hectares) }\end{array}$ & $\begin{array}{c}\text { Área de } \\
\text { Reserva Legal } \\
\text { (em hectares) }\end{array}$ \\
\hline Santa Apolônia & 26.577 & 21 & 0 & 0 \\
\hline $\begin{array}{c}\text { Antonio } \\
\text { Conselheiro II }\end{array}$ & 1.078 & 15 & 0 & 215 \\
\hline Alcídia da Gata & 462 & 19 & 14 & 72 \\
\hline
\end{tabular}

Fonte: Censo da Reforma Agrária de 2002

Org. Nivea Massaretto

No quadro 1, percebe-se que no Assentamento Santa Apolônia não há registro de APP nem de Reserva Legal. Já no Assentamento Alcídia da Gata, 3\% da área total se destina a APP e 15,6\% para Reserva Legal, totalizando 18,6\% de áreas que não podem sofrer intervenções antrópicas. No assentamento Antonio Conselheiro II, quase metade da área total, 46,5\%, se destina à Reserva Legal. 
Os dados do Censo também mostram que não houve área desmatada após a criação dos assentamentos e, ainda, ocorreu uma pequena iniciativa de melhoria ambiental, entre 0-20\% nos assentamentos Santa Apolônia e Antonio Conselheiro II.

O quadro 2 apresenta as características de infraestrutura dos assentamentos.

Quadro 2. Características de infraestrutura das famílias.

\begin{tabular}{|c|c|c|c|c|}
\hline $\begin{array}{c}\text { Nome do } \\
\text { Assentamento }\end{array}$ & $\begin{array}{c}\text { Famílias que } \\
\text { ocupam casas } \\
\text { definitivas de } \\
\text { alvenaria ou } \\
\text { de madeira }\end{array}$ & $\begin{array}{c}\text { Famílias com } \\
\text { abastecimento } \\
\text { regular de água } \\
\text { de boa qualidade }\end{array}$ & $\begin{array}{c}\text { Famílias que } \\
\text { ocupam casas } \\
\text { com sanitário } \\
\text { interno ou } \\
\text { externo ligado } \\
\text { à fossa séptica }\end{array}$ & $\begin{array}{c}\text { Famílias que } \\
\text { ocupam casas com } \\
\text { acesso ao } \\
\text { fornecimento } \\
\text { regular de energia } \\
\text { elétrica } \\
\text { convencional }\end{array}$ \\
\hline $\begin{array}{c}\text { Santa } \\
\text { Apolônia }\end{array}$ & $81-100 \%$ & Todas & $0-20 \%$ & $61-80 \%$ \\
\hline $\begin{array}{c}\text { Antonio } \\
\text { Conselheiro II }\end{array}$ & $81-100 \%$ & Nenhuma & Nenhuma & $81-100 \%$ \\
\hline $\begin{array}{c}\text { Alcídia da } \\
\text { Gata }\end{array}$ & $81-100 \%$ & $81-100 \%$ & $0-20 \%$ & $81-100 \%$ \\
\hline
\end{tabular}

Fonte: Censo da Reforma Agrária de 2002 Org. Nivea Massaretto

Observa-se que em relação às casas das famílias assentadas, a maioria apresenta casas definitivas de alvenaria ou de madeira. $\mathrm{O}$ abastecimento regular de água de boa qualidade é desigual entre os assentamentos, sendo que no Santa Apolônia todas as famílias tem abastecimento de boa qualidade, no Antonio Conselheiro II, ao contrário, nenhuma família e no Alcídia da Gata, a maioria possui um bom fornecimento.

Quanto a casa com sanitário interno ou externo ligado à fossa séptica, a maioria dos assentamentos tem um índice muito baixo, sendo que no Antonio Conselheiro II nenhuma família tem sanitário ligado à fossa séptica, mostrando assim, um grave problema ambiental nesses assentamentos. Já energia elétrica, todos os assentamentos apresentam percentual maior que $50 \%$ com acesso ao fornecimento regular de energia elétrica.

Em relação ao auxílio à produção e comercialização, os dados mostraram que os assentamentos têm poucas parcerias. Apenas o assentamento Santa Apolônia tem auxílio em parceria com o Governo Estadual, o que faz sentindo, já que se trata de um projeto de assentamento estadual e, o mais interessante, é o Alcídia da Gata, assentamento estadual, que tem parceria com INCRA, órgão federal, sendo que Antonio Conselheiro II, que é federal, não possui parceria com este órgão governamental. Sobre 
os processos de produção, não há nenhuma família, dentre os três assentamentos, que participa de cooperativas, seja dentro ou fora do próprio assentamento.

Os investimentos nestes assentamentos também são precários, por exemplo, o número de tratores existentes é muito baixo, sendo três nos assentamentos Santa Apolônia e Antonio Conselheiro II e nenhum no Alcídia da Gata, ou seja, apesar de possuir três tratores, quando comparamos com a área dos assentamentos, constata-se que o número é bem inexpressivo, tendo o Santa Apolônia uma área de 26.577 hectares e Antonio Conselheiro II área de 1.078 hectares, com lotes em média de 21 e 15 hectares, respectivamente.

O quadro 3 mostra as principais atividades desenvolvidas nos assentamentos.

Quadro 3. Principais atividades desenvolvidas nos assentamentos.

\begin{tabular}{|c|c|c|c|}
\hline $\begin{array}{c}\text { Nome do } \\
\text { Assentamento }\end{array}$ & $\begin{array}{c}\text { Famílias que tem } \\
\text { como principal } \\
\text { atividade a } \\
\text { produção para } \\
\text { subsistência }\end{array}$ & $\begin{array}{c}\text { Famílias que tem como } \\
\text { principal atividade de } \\
\text { geração de renda a produção } \\
\text { diversificada, combinando } \\
\text { diversos sistemas de } \\
\text { produção agrícola e/ou } \\
\text { pecuária e/ou extrativista }\end{array}$ & $\begin{array}{c}\text { Famílias que tem } \\
\text { como principal } \\
\text { atividade de geração } \\
\text { de renda a pecuária } \\
\text { bovina, caprina, } \\
\text { produção de leite, } \\
\text { etc. }\end{array}$ \\
\hline $\begin{array}{c}\text { Santa } \\
\text { Apolônia }\end{array}$ & $41-60 \%$ & $21-40 \%$ & $61-80 \%$ \\
\hline $\begin{array}{c}\text { Antonio } \\
\text { Conselheiro II }\end{array}$ & $21-40 \%$ & $21-40 \%$ & $41-60 \%$ \\
\hline $\begin{array}{c}\text { Alcídia da } \\
\text { Gata }\end{array}$ & $0-20 \%$ & $0-20 \%$ & $81-100 \%$ \\
\hline
\end{tabular}

Fonte: Censo da Reforma Agrária de $2002 \quad$ Org. Nivea Massaretto

Observa-se que uma boa parcela das famílias no assentamento Santa Apolônia tem como principal atividade a produção voltada à subsistência, mas o predomínio de geração de renda é de pecuária bovina, caprina e produção de leite. No assentamento Antonio Conselheiro II, a atividade com maior renda também é na atividade de pecuária e produção de leite, com índices em torno de $21-40 \%$ para atividades de subsistência e produção diversificada. No assentamento Alcídia da Gata a maioria das famílias, entre 81-100\% tem a pecuária e produção de leite como principal atividade. Atividades como avicultura, sinocultura e psicultura não é realizada por nenhuma família. 
Quadro 4. Produção dos assentamentos rurais.

\begin{tabular}{|c|c|c|c|}
\hline $\begin{array}{c}\text { Nome do } \\
\text { Assentamento }\end{array}$ & $\begin{array}{c}\text { Famílias que tem como } \\
\text { principal atividade de } \\
\text { geração de renda a } \\
\text { produção de lavouras de } \\
\text { grãos, tubérculos ou } \\
\text { plantas estimulantes: } \\
\text { mandioca, batata, cana- } \\
\text { de-açúcar, café, milho, } \\
\text { soja, mate, arroz, feijão, } \\
\text { trigo, etc }\end{array}$ & $\begin{array}{c}\text { Famílias que } \\
\text { tem como } \\
\text { principal } \\
\text { atividade de } \\
\text { geração de } \\
\text { renda a } \\
\text { fruticultura ou } \\
\text { horticultura }\end{array}$ & $\begin{array}{c}\text { Famílias que tem como } \\
\text { principal atividade de } \\
\text { geração de renda a } \\
\text { produção de bens } \\
\text { processados ou } \\
\text { industrializados no local } \\
\text { como queijo, farinha de } \\
\text { mandioca, polpa de frutas } \\
\text { ou vassouras de sorgo }\end{array}$ \\
\hline $\begin{array}{c}\text { Santa } \\
\text { Apolônia }\end{array}$ & Nenhuma & $0-20 \%$ & $0-20 \%$ \\
\hline $\begin{array}{c}\text { Antonio } \\
\text { Conselheiro II }\end{array}$ & $0-20 \%$ & Nenhuma & Nenhuma \\
\hline $\begin{array}{c}\text { Alcídia da } \\
\text { Gata }\end{array}$ & Nenhuma & Nenhuma & Nenhuma \\
\hline
\end{tabular}

Fonte: Censo da Reforma Agrária de $2002 \quad$ Org. Nivea Massaretto

No quadro 4, acima, interessante observar que nenhum assentamento tem expressiva produção voltada à lavoura de grãos, tubérculos ou plantas estimulantes, características que são encontradas facilmente na produção familiar, mas não nestes três casos. A fruticultura, horticultura e bens processados também são poucos expressivos. Possivelmente, estes assentamentos têm essas culturas em seus lotes, mas para subsistência.

Quadro 5. Renda das famílias dos assentamentos rurais.

\begin{tabular}{|c|c|c|c|c|}
\hline $\begin{array}{c}\text { Nome do } \\
\text { Assentamento }\end{array}$ & $\begin{array}{c}\text { Famílias que } \\
\text { tem renda } \\
\text { complementar } \\
\text { gerada dentro } \\
\text { ou fora do } \\
\text { assentamento } \\
\text { com qualquer } \\
\text { trabalho } \\
\text { agrícola de } \\
\text { diarista, safrista } \\
\text { ou empregado }\end{array}$ & $\begin{array}{c}\text { Famílias que } \\
\text { tem renda } \\
\text { complementar } \\
\text { gerada dentro } \\
\text { do assentamento } \\
\text { com atividades } \\
\text { não agrícolas } \\
\text { como a costura, } \\
\text { o artesanato, } \\
\text { comércio de } \\
\text { produtos não } \\
\text { agrícolas, } \\
\text { serviços não } \\
\text { agrícolas }\end{array}$ & $\begin{array}{c}\text { Famílias que } \\
\text { tem renda } \\
\text { complementar } \\
\text { gerada fora do } \\
\text { assentamento } \\
\text { com atividades } \\
\text { não agrícolas }\end{array}$ & $\begin{array}{c}\text { Famílias que tem } \\
\text { renda gerada } \\
\text { por outros } \\
\text { benefícios do } \\
\text { Governo como } \\
\text { pensões, } \\
\text { aposentadoria, } \\
\text { bolsa-escola, } \\
\text { vale-gás ou outro } \\
\text { benefício }\end{array}$ \\
\hline $\begin{array}{c}\text { Santa } \\
\text { Apolônia }\end{array}$ & $0-20 \%$ & Nenhuma & Nenhuma & $41-60 \%$ \\
\hline $\begin{array}{c}\text { Antonio } \\
\text { Conselheiro II }\end{array}$ & $41-60 \%$ & $0-20 \%$ & $0-20 \%$ & $41-60 \%$ \\
\hline $\begin{array}{c}\text { Alcídia da } \\
\text { Gata }\end{array}$ & $0-20 \%$ & $0-20 \%$ & $0-20 \%$ & $0-20 \%$ \\
\hline
\end{tabular}

Fonte: Censo da Reforma Agrária de 2002

Org. Nivea Massaretto 
Analisando o quadro 5, observa-se que a renda gerada dentro e fora do assentamento com trabalho agrícola não é muito expressiva nos assentamentos estaduais, mas o percentual já é maior no assentamento federal. As atividades geradas dentro e fora do assentamento com atividades não agrícolas também são inexpressivas. Já a renda gerada com outros benefícios do governo chega a $60 \%$ no caso do Santa Apolônia e Antonio Conselheiro II, sendo Alcídia da Gata com um valor entre 0-20\%.

Quadro 6. Comercialização dos produtos.

\begin{tabular}{|c|c|c|c|}
\hline $\begin{array}{c}\text { Nome do } \\
\text { Assentamento }\end{array}$ & $\begin{array}{c}\text { Famílias que } \\
\text { comercializam seus } \\
\text { produtos em } \\
\text { mercados locais ou } \\
\text { nas vizinhanças do } \\
\text { assentamento }\end{array}$ & $\begin{array}{c}\text { Famílias que } \\
\text { comercializam seus } \\
\text { produtos por } \\
\text { atravessadores }\end{array}$ & $\begin{array}{c}\text { Famílias que } \\
\text { comercializam seus } \\
\text { produtos em } \\
\text { sistemas integrados } \\
\text { com agroindústrias } \\
\text { ou com contratos de } \\
\text { venda antecipada }\end{array}$ \\
\hline Santa Apolônia & Nenhuma & $41-60 \%$ & Nenhuma \\
\hline $\begin{array}{c}\text { Antonio Conselheiro } \\
\text { II }\end{array}$ & Nenhuma & $81-100 \%$ & $41-60 \%$ \\
\hline Alcídia da Gata & Nenhuma & $41-60 \%$ & Nenhuma \\
\hline
\end{tabular}

Fonte: Censo da Reforma Agrária de $2002 \quad$ Org. Nivea Massaretto

No quadro 6, o que mais chama atenção é o fato da não comercialização de produtos em mercados locais ou nas vizinhanças do assentamento, mas um valor expressivo de comercialização por atravessadores, sendo entre 81-100\% no Antonio Conselheiro II e entre 41-60\% nos assentamentos estaduais. A venda antecipada também é pouco utilizada pelos assentamentos Santa Apolônia e Alcídia da Gata, mas é utilizado pela maioria das famílias no Antonio Conselheiro II.

Quando perguntado aos beneficiários sobre a renda total gerada pela família, somando tudo o que elas ganham, produzem ou tem de benefícios, as respostas variaram entre: "Insuficiente para suprir as necessidades básicas de alimentação e de saúde" e "Suficiente para suprir as necessidades básicas de alimentação e insuficientes para as necessidades de saúde", sendo que não houve nenhuma resposta em que a afirmação fosse positiva para a renda. Isso pode ser entendido melhor quando verificada a renda por mês dessas famílias, sendo de $\mathrm{R} \$ 150,00$ no assentamento Santa Apolônia e $\mathrm{R} \$ 100,00$ nos assentamentos Antonio Conselheiro II e Alcídia da Gata.

Mais especificamente sobre o acesso ao crédito, o quadro 7 mostra o percentual de famílias que tiveram acesso, parcial ou total do crédito para aquisição de material de construção e outros relacionados aos programas do governo. 
Quadro 7. Acesso ao crédito das famílias assentadas.

\begin{tabular}{|c|c|c|c|c|}
\hline $\begin{array}{c}\text { Nome do } \\
\text { Assentamento }\end{array}$ & $\begin{array}{c}\text { Famílias que } \\
\text { já } \\
\text { receberam } \\
\text { total ou } \\
\text { parcialmente } \\
\text { o crédito } \\
\text { para } \\
\text { aquisição de } \\
\text { material de } \\
\text { construção }\end{array}$ & $\begin{array}{c}\text { Famílias que } \\
\text { já } \\
\text { receberam } \\
\text { total ou } \\
\text { parcialmente } \\
\text { o crédito de } \\
\text { apoio à } \\
\text { instalação } \\
\text { para compra } \\
\text { de alimentos } \\
\text { e início das } \\
\text { atividades } \\
\text { produtivas }\end{array}$ & $\begin{array}{c}\text { Famílias } \\
\text { que já } \\
\text { receberam } \\
\text { o PRONAF } \\
\text { A ou antigo } \\
\text { PROCERA }\end{array}$ & $\begin{array}{c}\text { Famílias } \\
\text { que já } \\
\text { receberam } \\
\text { o } \\
\text { PRONAF } \\
\text { C ou D }\end{array}$ \\
\hline $\begin{array}{c}\text { Santa } \\
\text { Apolônia } \\
\end{array}$ & Nenhuma & $0-20 \%$ & $61-80 \%$ & $0-20 \%$ \\
\hline $\begin{array}{c}\text { Antonio } \\
\text { Conselheiro } \\
\text { II }\end{array}$ & $81-100 \%$ & $81-100 \%$ & $81-100 \%$ & $0-20 \%$ \\
\hline $\begin{array}{c}\text { Alcídia da } \\
\text { Gata }\end{array}$ & Nenhuma & Nenhuma & $81-100 \%$ & $0-20 \%$ \\
\hline
\end{tabular}

Fonte: Censo da Reforma Agrária de $2002 \quad$ Org. Nivea Massaretto

Observa-se que os assentamentos estaduais não obtiveram crédito de aquisição de material de construção, já Antonio Conselheiro II, que é federal, obteve o crédito. Conforme descrito anteriormente, este crédito seria oferecido no momento em que estivessem em seus lotes para que, após a instalação, as famílias tivessem acesso ao PROCERA, contudo, este aspecto não foi cumprido pelos órgãos governamentais, o que dificulta e prova que os assentados recebem seus lotes sem qualquer infra-estrutura e auxílio financeiro.

Em todos os assentamentos, a maioria das famílias recebeu crédito do PRONAFA (exclusivo para assentados) ou do antigo PROCERA. Em relação ao PRONAF C ou D, poucas famílias obtiveram crédito, o que é justificável pela renda apresentada no quadro 7, em que a renda anual desses assentados não ultrapassa a $\mathrm{R} \$ 1.800,00 \mathrm{e}$, para ter acesso ao PRONAF C, é exigido que obtenham renda bruta anual familiar acima de $\mathrm{R} \$ 2.000,00$ e até $\mathrm{R} \$ 14.000,00$, excluídos os proventos vinculados aos benefícios previdenciários decorrentes de atividades rurais e do PRONAF D renda bruta anual familiar acima de $\mathrm{R} \$ 14.000,00$ e até $\mathrm{R} \$ 40.000,00$, incluída a renda proveniente de atividades desenvolvidas no estabelecimento e fora dele, por qualquer componente da 
família, excluídos os benefícios sociais e os proventos previdenciários decorrentes de atividades rurais.

$\mathrm{E}$, por final, os dados do censo mostraram que os assentados não possuem assistência técnica regular, seja de Eng. Agrônomo, técnico agrícola, veterinário, Eng. Ou técnico florestal do Estado, Prefeitura ou INCRA.

\section{OS PROGRAMAS DE FINANCIAMENTO E O CASO DOS ASSENTAMENTOS RURAIS DO PONTAL DO PARANAPANEMA: AS DIFICULDADES E OS DESAFIOS}

Visto as características dos programas de financiamento, seus limites e impasses e os dados do Censo da Reforma Agrária, pode-se fazer algumas considerações.

A primeira delas é a distância entre a realidade e aquilo que está documentado, ou seja, os programas do governo buscam auxiliar a agricultura familiar, melhorando seus rendimentos e a comercialização de seus produtos, no entanto, acabam priorizando aqueles que já têm certo nível de desenvolvimento com a sua produção, questão que foi relatado por vários autores como Bruno \& Dias e também no trabalho de Corrêa \& Silva, em que as autoras afirmam que existe uma forte concentração do crédito para culturas ligadas à exportação e às agroindústrias, enquanto os produtos voltados para o abastecimento interno, gerados especialmente, por pequenos produtores ficam em segundo plano. Assim, o acesso continua se concentrando para os grandes produtores e para os produtos com alto grau de integração.

Outra distância entre teoria e realidade pode ser encontrada nas respostas dadas pelos beneficiários e pelos responsáveis sociais. Um exemplo é a capacidade do número de famílias dos assentamentos dados pela portaria da criação e o número de famílias informado pelos assentados, no qual é superior à capacidade. Nota-se a dificuldade que os responsáveis pelos projetos de assentamentos têm para manterem atualizados os seus dados sobre assentamentos. Um fato bastante negativo, pois se existisse um banco de dados sempre atualizado, os futuros projetos e programas poderiam ser feitos baseados na realidade de cada assentamento, mas isso fica impossível sem atualizações.

O que pôde ficar evidenciado foi a dificuldade do acesso ao crédito. Segundo Nascimento et al (2007), existem dificuldades geradas pelas instituições financeiras e outras que o próprio produtor gera e que enfrenta. Por um lado, os assentados já 
enfrentam dificuldades no início da transação: a documentação exigida. Os agricultores, muitas vezes não possuem nem documentos pessoais, quanto mais fiscais e tributários, ou seja, falta iniciativa dos agricultores para realizar suas contabilidades agrícolas (CARDOSO, 1985). Além disso, as taxas de juros são elevadas, pois, como descrito anteriormente, com o PRONAF, os bancos assumiram maiores riscos, criando exigências e dificuldades aos menos desenvolvidos. Outro fato é que, como as agências não vão até os agricultores, estes precisam gastar tempo e dinheiro para se deslocarem até as agências, sendo que no caso desses assentamentos selecionados, o centro do município fica a uma hora dos assentamentos e o transporte municipal passa apenas uma vez por semana nos assentamentos.

Do outro lado, os bancos, seguindo a lógica dominante da atividade financeira, só oferecem crédito àquele que apresentar melhores rendimentos e garantias. Esta questão se torna um grande impasse dos programas, pois aqueles a quem o programa se destina, agricultura familiar e pequenos produtores, não oferecem garantias e não possuem renda elevada. Neste sentido, Marino et al, apresentam três peculiaridades que envolvem essa questão: i) o agente financeiro enfrenta dificuldades na obtenção de informações dos produtores; ii) incapacidade do credor para monitorar e controlar a aplicação dos recursos; iii) as garantias do produtor não são suficientes para o agente financeiro. O banco, obcecado pela lógica dominante, não percebe que o trabalho, a exploração da agricultura familiar é diferente e acabam tratando com um grau de autoridade e criando um pré-conceito de que todo pequeno produtor não sabe gerenciar. Além disso, a atividade do setor agropecuário tem um risco muito grande, principalmente em relação às condições climáticas, o que faz com que os bancos dificultem ainda mais a liberação do financiamento.

Os autores Bruno \& Dias, destacam no relatório que em muitos casos ocorre a demora na liberação, contratação e pagamentos do financiamento, no qual, muitas vezes o dinheiro é liberado depois do período do ciclo produtivo. Este é um fato bastante negativo, pois passado o período produtivo, os agricultores não terão uma eficiência na produção, o que produzirá um reflexo direto no pagamento do financiamento, causando muitas inadimplências.

Com os dados do Censo, observa-se que os assentados encontram dificuldades para iniciar a construção de suas casas e produção. Conforme visto, nos dois assentamentos estaduais não houve recebimento de crédito para aquisição de material de construção, ou seja, uma primeira dificuldade. A segunda é que os assentamentos estão 
localizados em solos bastante arenosos e de baixa fertilidade, o que necessitam de uma boa correção desses solos, porém, os assentados não recebem auxílio para isso e, mesmo tendo crédito de apoio para compra de alimentos e início das atividades produtivas, muitas vezes essa questão não é mencionada. Vimos também que a maioria obteve acesso ao PRONAF A ou antigo PROCERA, entretanto, o PRONAF C e D poucos tiveram acesso, o que possivelmente se justifica pelo baixo rendimento mensal das famílias. Dessa forma, como essas famílias conseguirão um financiamento se elas mesmas já declararam que a renda é insuficiente?

Falta mais incentivo quanto ao investimento. A tecnologia está moderna, mas não chega a esses agricultores familiares. Além disso, falta incentivo na comercialização, que é um dos objetivos do programa, mas que ao vermos os dados, grande parte das famílias comercializam seus produtos por atravessadores, o que é extremamente negativo para os assentados, já que os atravessadores acabam pagando bem menos do que a produção realmente vale. De nada adianta o assentado ter acesso ao crédito, mas não ter incentivo à comercialização.

Uma última consideração diz respeito à assistência técnica. Os assentados necessitam de apoio técnico para terem uma excelente produção, entretanto, não é o que acontece. Os dados mostraram que os assentados não possuem assistência técnica regular, seja de Eng. Agrônomo, técnico agrícola, veterinário, Eng. ou técnico florestal do Estado, Prefeitura ou INCRA. Por outro lado, sabe-se também que o número de funcionários dos órgãos governamentais: INCRA, ITESP e até mesmo prefeitura, são insuficientes para atender à demanda dos assentamentos rurais.

\section{CONSIDERAÇÕES FINAIS: POSSÍVEIS SOLUÇÕES}

Diante do exposto, conclui-se que os programas de financiamento feitos para atender aos pequenos produtores e agricultores familiares têm em sua formulação os elementos importantes para o desenvolvimento desses agricultores. Representa uma alternativa muito positiva para o financiamento do setor rural, entretanto, na prática não está conseguindo atingir seus principais objetivos.

As afirmações apresentadas mostram que nossas hipóteses iniciais são coerentes com a realidade, visto que os assentados encontram muita dificuldade em obter o crédito rural e, as parcerias foram vistas com bons olhos, pois eliminaria toda a burocracia que 
existe ao tentar um financiamento e, por isso, foi o caminho mais viável. A hipótese de que os programas ainda estão voltados àqueles que já possuem um grau de desenvolvimento e não para aqueles que estão iniciando sua produção no campo, também pôde ser confirmada através dos dados mostrados no decorrer deste trabalho e, por último, a hipótese de que as condições físicas e químicas, somados à falta de recursos, capacitação técnica, influenciam na produção e desenvolvimento desses assentados também foi confirmada.

Dois problemas são importantes para a solução desses impasses. O primeiro é em relação a alguns assentados que, ao adquirirem seus lotes, deixam de buscar melhorar cada vez mais suas condições, ou seja, assentados que não estão felizes, mas que também não se unem aos demais assentados para continuar a luta na terra. Muitos até deixam de participar das reuniões mensais que acontecem nos assentamentos, enfraquecendo o movimento. O segundo problema é como o assentado dará garantias às instituições financeiras com uma renda mensal entre $\mathrm{R} \$ 100,00$ a $\mathrm{R} \$ 150,00$, no caso dos três assentamentos selecionados.

Pensando nisso, temos algumas possíveis soluções para resolver esses impasses. $\mathrm{Na}$ obtenção do financiamento, os custos de transação precisam ser reduzidos. Antes de tudo, é preciso que todos os assentados recebam crédito, por parte do Governo, para aquisição de materiais de construção e para o início das atividades produtivas para que consigam ter e aumentar sua renda gradativamente para assim ter acesso a um crédito maior junto às instituições financeiras.

$\mathrm{Na}$ obtenção do financiamento, a documentação exigida deve ser bastante esclarecida e mais simples para os agricultores familiares, neste caso os assentados, dentre elas, Declaração de Concessionário do Programa Nacional de Reforma Agrária; Residir na propriedade; Declaração de aptidão de produtor rural (para comprovação de renda e aptidão de agricultor); Plano de Custeio (metas e orçamento); Seguro Rural da produção financiada, sendo que o valor do seguro seria descontado do valor do financiamento, ou seja, uma parte do valor do financiamento ficaria retido para o seguro rural, além disso, os custos de transação precisam ser reduzidos.

Como as instituições financeiras têm dificuldades para monitorar e controlar a aplicação dos recursos, deve ser exigida a documentação de compra dos recursos para a produção a ser realizada, adquiridos com o financiamento e visitas mensais à agência financiadora para entrega de relatórios mensais. Essa poderia ser uma forma de controle pelo credor e uma forma de garantia. É preciso pensar em formas de retorno para que os 
bancos não assumam muitos riscos e, assim, diminuam as taxas de juros e melhorem as formas de pagamento, para isso, é preciso intervenção do Estado. O credor também deve oferecer incentivo para aqueles que pagam em dia, como uma diminuição do valor a ser pago.

A liberação do crédito não pode atrasar, precisa estar de acordo com o ciclo produtivo para que os assentados tenham eficiência na produção. Após esta etapa, é necessário um forte incentivo em relação à comercialização e, nesse sentido, parcerias com prefeituras (escolas e feiras) e as compras antecipadas parecem boas opções para vencer os atravessadores. Desta forma, com o crédito chegando no momento adequado, eficiência de produção e comercialização, os assentados terão a melhoria de suas rendas.

Extremamente importante resolver a questão da falta de assistência técnica, imprescindível aos assentados, que na maioria das vezes não tem conhecimento. Esse auxílio deverá ser efetuado antes, durante e após o financiamento, auxiliando em questões como a elaboração do projeto de financiamento, correção e manejo adequados do solo, administração dos recursos: (compras e vendas).

Sobre a produção, observou-se predomínio de geração de renda com a pecuária bovina, caprina e produção de leite, ou seja, é um caso diferente do que ocorre com a maioria dos agricultores familiares que tem maior produção relacionada aos produtos de alimentação básica. Assim, é preciso de mais investimentos além da produção voltada à lavoura de grãos, tubérculos ou plantas estimulantes, mas também ao setor pecuário. Vimos também que poucas famílias tem produção de fruticultura, horticultura e bens processados, produtos esses que se forem investidos podem render. Nesse sentido, sugerimos como uma grande saída para a melhoria de renda dos assentados, a diversificação de culturas, pois, caso ocorra imprevistos, como mercado instável de determinado produto, o assentado sempre poderá contar com outro produto, não correndo risco de perca total de sua produção.

Ainda em relação à produção, em trabalho feito por Briggeman \& Akers (2010), constatou-se que produtores, no norte dos EUA, que possuem, além de atividades agrícolas, atividades não-agrícolas, ampliam seus rendimentos. Dessa forma, incentivar atividades não-agrícolas, mas dentro de seus próprios lotes, podem fortalecer ainda mais a agricultura familiar.

Outra questão a ser solucionada é sobre a dimensão ambiental desses assentamentos. Conforme demonstrado pelos dados, nos três assentamentos, a maioria 
não possui casas com sanitário interno ou externo ligado à fossa séptica, tornando um grave problema ambiental. Para isso, seria necessário fornecer o crédito para aquisição de materiais de construção, já incentivando uma construção mais adequada de suas casas, principalmente em relação aos sanitários.

Apesar dos assentamentos apresentarem este problema ambiental, percebe-se um aspecto positivo em relação à questão ambiental, já que após suas criações não houve desmatamento e em alguns casos houve até projetos de melhorias ambientais, desta forma, os assentamentos podem ser mantenedores da cobertura natural, o que não ocorre com as grandes propriedades de monoculturas que estão expandindo cada vez mais, como o caso da cana-de-açúcar na própria região do Pontal do Paranapanema.

Finalmente, uma última sugestão seria o incentivo intenso na formação de cooperativas agrícolas. Em trabalho de Nascimento et al (2007), os autores concluíram que muitas são as formas de programas e financiamentos, públicos e privados, porém são de difícil acesso aos pequenos produtores e a maioria deles não conhecessem aquilo que podem lhes auxiliar e, nesse sentido, a associação em cooperativas pode ser positiva, pois pode se contratar pessoas especializadas nessa questão que auxiliem os agricultores, já que individualmente fica mais difícil. Em trabalho de Gimenes et al (2008), os autores também mostram a importância das cooperativas agropecuárias e o seu papel junto aos produtores rurais e instituições financeiras, pois se torna uma alternativa, principalmente aos pequenos produtores, já que estes não conseguem financiamento em bancos.

Acreditamos que cabe ao Estado voltar a apoiar, de maneira significativa, o setor agropecuário, afinal, a alimentação básica do brasileiro são advindas desse setor. É dever do Estado auxiliar os produtores rurais que, além das dificuldades econômica, social, ainda sofrem com as instabilidades climáticas.

\section{REFERÊNCIAS}

AB'SABER, A. N. Um conceito de geomorfologia a serviço das pesquisas sobre o quaternário. Geomorfologia, São Paulo, no 18, p. 1-23, 1969.

BARRETO, M. J; OLIVEIRA, A. M. S. de; THOMAZ JÚNIOR, A. Dinâmica geográfica da expansão da agroindústria canavieira no Pontal do Paranapanema e os desdobramentos para o trabalho: os casos da Usina Alvorada do Oeste e da Destilaria Decasa. In: VIII Jornada do Trabalho, 2007, Presidente Prudente. Anais da VII Jornada do Trabalho, 2007. 
BRIGGEMAN, B. C.; AKERS, M. M. The credit advantage of farm and rural small business ownership. In: Agricultural Finance Review. Vol.70 No.3, 2010. pp.353-364

BERTONI, J. e LOMBARDI NETO, F. Conservação do solo. São Paulo: Ícone, 1990. $355 \mathrm{p}$.

BRUNO, R. A. L.; DIAS, M. M. As políticas públicas de crédito para os assentamentos rurais no Brasil: Relatório de Consultoria. Rio de Janeiro, Agosto de 2004.

CARDOSO, J. L. CREDITO RURAL: Um elemento de diferenciação dos pequenos produtores? In. Revista Perspectivas, São Paulo. 8: 85-93, 1985.

CORRÊA, V. P.; SILVA, F. F. O novo desenho do Financiamento Agrícola e as dificuldades para os produtores não integrados.

FERNANDES, B. M.; GOLÇALVES, E. C. Políticas de agrocombustíveis no Brasil: paradigmas e disputa territorial. Inédito.

GIMENES, R. M. T.; GIMENES, F. P.; GOZER, I. C. Evolução do crédito rural no Brasil e o papel das cooperativas agropecuárias no financiamento dos produtores rurais. In: XLVI Congresso da Sociedade Brasileira de Economia, Administração e Sociologia Rural. Acre, 20 a 23 de julho de 2008.

GONÇALVES, E. C. A disputa territorial entre movimentos camponeses e agronegócio sucroalcooleiro: a "parceria" dos assentados com usinas de açúcar e álcool no Pontal do Paranapanema- SP. Inédito.

ITESP. Fundação Instituto de Terras e São Paulo "José Gomes da Silva”. Portaria Itesp - 75, de 27-10-2002. Plantio de Culturas.

ITESP. Fundação Instituto de Terras e São Paulo "José Gomes da Silva”. Portaria Itesp - 77, de 27/07/2004

INSTITUTO DE PESQUISA TECNOLÓGICAS DO ESTADO DE SÃO PAULO. Mapa geológico do Estado de São Paulo. São Paulo, 1981. Escala 1:500.000.

LEITE, José Ferrari. A ocupação do Pontal do Paranapanema. São Paulo: Hucitec, 1998. p.202.

MARINO, M. K.; ZYLBERSZTAJN, D. ALMEIDA, L. F. Access Costs in Agricultural Credit in Brazil. IAMA 2005

MASSARETTO, N. Impactos ambientais do plantio da cana-de-açúcar nos solos dos assentamentos rurais do Pontal do Paranapanema - São Paulo. Monografia de bacharelado. Presidente Prudente, 2010.

NASCIMENTO, A. F.; PIZAIA, M. G.; CAMARA, M. R. Fontes de financiamento da agricultura brasileira. In: XLV Congresso da Sociedade Brasileira de 
Economia, Administração e Sociologia Rural. Londrina, 22 a 25 de julho de 2007.

NEUMANN, P. S.; DIESEL, V. O problema da não definição da unidade econômica básica na agricultura. Palestra apresentada Congresso da Sociedade Brasileira de Economia, Administração e Sociologia Rural. Disponível em: < http://www.sober.org.br/palestra/5/1180.pdf>. Acesso em 25/01/2013.

OLIVEIRA, J.B. Solos do estado de São Paulo: descrição das classes registradas no mapa pedológico. Campinas, Bol. Ci., n. 45, IAC. 1999. 108p.

SILVA ET AL. RELATÓRIO DE IMPACTOS SOCIOTERRITORIAIS - RIST Desenvolvimento territorial e políticas públicas no Pontal do Paranapanema. Presidente Prudente, 2006.

ROSS, J.L.S. e MOROZ, I.C. Mapa geomorfológico do Estado de São Paulo. Revista do Departamento de Geografia, São Paulo, n.10, p.41-56, 1996.

SILVA, A. A. da; FERNANDES, B. M.; VALENCIANO, R. C. Desenvolvimento territorial e políticas públicas no Pontal do Paranapanema. Presidente Prudente: Nera/Incra, 2006.

SPAROVEK, Gerd. Censo da Reforma Agrária, 2002: Módulo Projetos (Banco de dados). Piracicaba: Escola Superior de Agricultura Luiz de Queiroz (ESALQUSP); Núcleo de Estudos Agrários e Desenvolvimento Rural (NEAD/MDA); Instituto Brasileiro de Geografia e Estatística (IBGE), 2002. Consórcio de Informações Sociais, 2005. Disponível em: $<$ http://www.cis.org.br $>$. Acesso em 04/04/2011. 